\title{
Language control in different contexts: the behavioral ecology of bilingual speakers
}

\section{David William Green*}

Department of Cognitive, Perceptual and Brain Sciences, University College London, London, UK

\section{Edited by:}

Guillaume Thierry, Bangor University, UK

\section{Reviewed by:}

Katherine Midgley, Tufts University, USA

Niels O. Schiller, University of Leiden, Netherlands

*Correspondence:

David William Green, Department of Cognitive, Perceptual and Brain

Sciences, University College London, London WC1E 6BT, UK.

e-mail:d.w.green@ucl.ac.uk
This paper proposes that different experimental contexts (single or dual language contexts) permit different neural loci at which words in the target language can be selected. However, in order to develop a fuller understanding of the neural circuit mediating language control we need to consider the community context in which bilingual speakers typically use their two languages (the behavioral ecology of bilingual speakers). The contrast between speakers from code-switching and non-code-switching communities offers a way to increase our understanding of the cortical, subcortical and, in particular, cerebellar structures involved in language control. It will also help us identify the non-verbal behavioral correlates associated with these control processes.

Keywords: language control, code-switching, language context, lexical selection, behavioral ecology
Functional neuroimaging studies have identified neural regions associated with interference between languages (e.g., RodriguezFornells et al., 2002; Kovelman et al., 2008) and with switching between languages both in reception (e.g., Crinion et al., 2006; Abutalebi et al., 2007; Nakamura et al., 2010) and in production (e.g., Hernandez et al., 2000; Abutalebi et al., 2008). Our current understanding is nonetheless constrained because we have not explored the extent to which differences in the community use of two languages (the behavioral ecology of bilingual speakers) affects the processes of language control. Bilingual communities differ: Some avoid switching between languages, others code-switch. Might the behavioral ecology shape the neural circuit involved in language control? Current neuroimaging data suggest it might.

We first contrast a context in which speakers switch on demand between two languages in naming simple objects with one in which they use just one language throughout an experimental session (see Grosjean, 1998; Wu and Thierry, 2010a on the importance of context to theoretical accounts of language control). These different contexts, we suggest, impose a different load on components of the control circuit. Switching increases demand on specific frontal and subcortical regions. In this dual language context, selection of the target word may occur late in the sequence of production. In contrast, in a single language context, selection may occur early and be mediated primarily by frontal regions. How general is this prediction? As a next step, we ask whether it applies to speakers in communities that code-switch. Such speakers recruit and adapt expressions from each language. Late, rather than early word selection may be the norm for them even in single language contexts. The neural bases of code-switching is not known but neuropsychological data (e.g., Marien et al., 2001) suggest that the right cerebellum plays an important role in the processing of morphosyntax. Given that code-switching involves adapting morphosyntax, the right cerebellum is likely to be an important component of neural circuit controlling code-switching. The third section draws out the value of studying the language control circuits in speakers from different behavioral ecologies. Functional studies need to include cerebellar structures if we are to enhance our understanding of the circuits involved in language control and the patterns of cognitive advantages.

\section{LANGUAGE CONTROL IN DUAL AND SINGLE LANGUAGE CONTEXTS}

Speaking one language rather than another involves selecting and articulating words that meet the intended meaning. The precise way in which this process is controlled may depend on the language context. We contrast a context in which a speaker uses just one of their languages to name objects in an experimental session with one where they are required to switch between languages on the basis of a color cue. For example, blue may signal that the picture is to be named in Italian whereas red may signal that it is to be named in German. In principle, only one language need be active in the single language context whereas both languages must be active in the dual language context. However, research indicates that the languages of bilingual speakers can be jointly active (e.g., Dijkstra et al., 1998; Van Hell and Dijkstra, 2002; Von Studnitz and Green, 2002, see van Heuven and Dijkstra, 2010 for a review) at least to the level of phonology even in a context that requires just a single language (Wu and Thierry, 2010b).

Given joint activation, bilingual speakers may resolve language conflict by suppressing the non-target language at some locus (Green, 1986, 1998; Linck et al., 2009; Philipp and Koch, 2009; Macizo et al., 2010; Snyder et al., 2010; Hoshino and Thierry, 2011) or by restricting competition to words within the target language in some other manner (e.g., Costa and Caramazza, 1999; Elston-Güttler, et al., 2005; Finkbeiner et al., 2006, see Bialystok et al., 2009, for a fuller discussion). Does this mean then that the selection process is identical in the single language and in the dual language context? No. There can be different loci of selection (e.g., Kroll et al., 2006; Abutalebi and Green, 2007). We take as our point of departure the idea that language 
control involves a cortical-subcortical circuit (Abutalebi and Green, 2007, 2008) and consider whether or not language context (single or dual) modulates activity in the circuit.

A major cue is that regions in the left inferior frontal cortex, anterior cingulate cortex (ACC) and caudate respond differently as a function of the experimental context. In a dual language context, where participants are required to use both languages in naming simple objects, all three regions activate during language switching (e.g., Abutalebi et al., 2008). Strikingly, this pattern of activity is absent for the same L1 nouns when participants name them in L1 in a context in which they must either name the object or generate a verb associated with it. Response in the caudate appears particularly sensitive to language switching because it is not observed when the context does not require switching (e.g., Rodriguez-Fornells et al., 2002; Kovelman et al., 2008).

We find direct corroboration when, as per the injunction in Wu and Thierry (2010a), bilingual speakers use just one of their languages throughout the entire experimental session. In this single language context, the anterior cingulate and caudate are not significantly activated when participants name pictures and activation in these regions does not differ from that found in monolingual speakers (Green et al., 2011). There is however increased activation in left prefrontal regions compared to that shown in monolingual speakers. Why might this be?

We have to distinguish between activation correlated with interference and activation associated with the control of interference. We found that regional activation in left pars opercularis (BA44) and left pars triangularis (BA 45) was inversely related to the size of the Stroop interference shown by monolingual participants outside the scanner. That is, the higher the activation the smaller the interference. Such an outcome suggests that these regions are involved in the control of interference. Regional activation in bilingual speakers relative to monolingual speakers may also reflect differences in the experienced frequency of words (as in the "weaker links" hypothesis, Gollan et al., 2008). However, a frequency-based account is an insufficient explanation because it presupposes that only a single language is selected and is silent on how such selection is achieved.

How then are we to explain the differential response of the control circuit to the different language contexts? One possibility is that it reflects the stage at which alternate words are gated from production (early or late). A single language context may afford early selection of the intended word mediated by the inferior frontal cortex. Alternate words in the other language are blocked at this stage and other structures such as the caudate are not activated. By contrast, in the dual language context, switch trials may necessarily require late selection. On a switch trial, the object name, consistent with the previous language, may be released for production because the new language task has yet to dominate. However, it is incorrect and so must be gated from production. In such a context, the caudate is also recruited. Response of the circuit is similar to that shown when individuals respond on incongruent trials in the Stroop task. Here, participants must suppress an incorrect response derived from the written word. Suppressing such interference activates the caudate as well as frontal regions (Ali et al., 2010).

The experimental context is not the only relevant factor in the response of the control circuit. Two other factors are pertinent: The speaker's proficiency in their second language and, separately, the behavioral ecology of a proficient bilingual speaker. Caudate activity may be expected in picture naming even in a single language context when speakers are not very proficient in their second language because they will tend to generate the first language name by default. However, the claim that context affects the locus of selection predicts that the caudate response will be even greater when such speakers perform in a dual language context. Where speakers are proficient in both languages their pattern of language use within their bilingual community may also be important in understanding the response of the control circuit. We discuss this possibility in the next section.

\section{LANGUAGE CONTROL AND CODE-SWITCHING}

We expect the contextual prediction to be met when participants are from communities that use one language at a time and switch to their other language when addressing a different addressee or when there is a change in topic. Such speakers are practiced at avoiding language conflict. In terms of the Abutalebi and Green $(2007,2008)$ model they recruit the ACC and left frontal cortex to monitor and to control their response (see Kerns et al., 2004). In contrast, in communities where individuals code-switch, language control is different (Green, 1998). Speakers have no need to avoid switching rather they freely exploit the activation of both languages. Their skill lies less in avoiding language conflict than in utilizing the joint activation of both languages and adapting their utterances appropriately. Consider an example from French-Alsatian codeswitched speech. Speakers adapt French verbs through the addition of a German particle (-ieren) as in "choisieren" from the French "choisir" rather than the German "wählen" (Edwards and GardnerChloros, 2007). For speakers from code-switching communities, speaking in just one language without code-switching is likely to be effortful. We might then expect them to show increased caudate response in the single language context compared to that shown by speakers from a non-code-switching community.

Fluent code-switching is likely to recruit other structures implicated in language control and so studying it is important. We do not know the neural bases of code-switching but we know that those who code-switch are adept at adapting words to the current syntactic context though of course there will be individual differences in the inventiveness of such code-switches. Neuropsychological data implicate cerebellar structures in the control of morphosyntax (Fabbro et al., 2000). For example, Silveri et al. (1994) found that damage to the right cerebellum led to morphological deficits including inappropriate substitutions of bound grammatical morphemes. The fundamental idea is that right cerebellum acts together with left frontal structures as part of a language control circuit (Fabbro et al., 2000). Critical support for this notion comes from data showing that damage to the right cerebellum suppresses activation in left frontal cortex and elicits aphasic symptoms. Reperfusion of the cerebellum reduces such symptoms (Marien et al., 2001).

Code-switching involves adapting morphosyntax. Given the neuropsychological data, we can predict that such adaptation will involve the right cerebellum. From a functional point of view, since code-switching involves the on-line adaptation of the morphosyntactic resources of each language, fluency in code-switching requires timing and synchronization - a role for which the cerebellum is also well suited (see Kotz and Schwartze, 2010 for an 
integrative framework). A plausible prediction from existing data is that code-switching is mediated by the co-activation of right cerebellar regions and left frontal cortex. Research on code-switching is therefore important for extending our understanding of language control in bilingual speakers and building on the model of Abutalebi and Green $(2007,2008)$.

\section{CONCLUSIONS AND PERSPECTIVES: THE BEHAVIORAL ECOLOGY OF THE BILINGUAL}

If functional demand shapes neural circuits then there may be structural correlates in the regions linked in control. In communities where speakers must switch on demand between their two languages, anterior cingulate and/or left inferior frontal regions may show greater gray matter density compared to monolingual speakers of just one of those languages. In contrast, in communities where bilinguals code-switch, right cerebellar structures may show enhanced gray matter density.

Recent research points to a bilingual advantage in controlling non-verbal interference (see Bialystok et al., 2009, for a review) attributable to the use of cognitive control processes in resolving language conflict. If code-switching utilizes the joint activation of two languages rather than suppresses one in favor of

\section{REFERENCES}

Abutalebi, J., Annoni, J. M., Seghier, M., Zimine, I., Lee-Jahnke, H., Lazeyras, F., Cappa, S. F., and Khateb, A. (2008). Language control and lexical competition in bilinguals: an eventrelated fMRI study. Cereb. Cortex 18 , 1496-1505.

Abutalebi, J., Brambati, S. M., Annoni, J. M., Moro, A., Cappa, S. F., and Perani, D. (2007). The neural cost of the auditory perception of language switches: an event-related fMRI study in bilinguals. J. Neurosci. 27, 13762-13769.

Abutalebi, J., and Green, D. W. (2007). Bilingual language production: the neurocognition of language representation and control. J. Neurolinguistics 20, 242-275.

Abutalebi, J., and Green, D. W. (2008). Control mechanisms in bilingual language production: neural evidence from language switching studies. Lang. Cogn. Process. 23, 557-582.

Ali, N., Green, D. W., Kherif, F., Devlin, J. T., and Price, C. J. (2010). The role of the left head of caudate in suppressing irrelevant words. J. Cogn. Neurosci. 22, 2369-2386.

Bialystok, E., Craik, F. I. M., Green, D. W., and Gollan, T. H. (2009). Bilingual minds. Psychol. Sci. Public Interest 10, 89-129.

Costa, A., and Caramazza, A. (1999). Is lexical selection in bilingual speech production language-specific? Further evidence from Spanish-English and English-Spanish bilinguals. Biling. Lang. Cogn. 2, 231-244.

Crinion, J., Turner, R., Grogan, A., Hanakawa, T., Noppeney, U., Devlin,
J. T., Aso, T., Urayama, S., Fukuyama, H., Stockton, K., Usui, K., Green D. W., and Price, C. J. (2006). Language control in the bilingual brain. Science 312, 1537-1540.

Dijkstra, T., van Jaarsveld, H., and ten Brinke, S. (1998). Interlingual homograph recognition: Effects of task demands and language intermixing. Biling: Lang. Cogn. 1, 51-66.

Edwards, M., and Gardner-Chloros, P. (2007). Compound verbs in code switching: bilinguals making do? Int. J. Biling. 11, 73-91.

Elston-Güttler, K. E., Gunter, T. C., and Kotz, S. A. (2005). Zooming into L2: global language context and adjustment affect processing of interlingual homographs in sentences. Brain Res. Cogn. Brain Res. 25, 57-70.

Fabbro, F., Moretti, R., and Bava, A. (2000). Language impairments in patients with cerebellar lesions. J. Neurolinguistics 13, 173-188.

Finkbeiner,M., Gollan, T., and Caramazza, A. (2006). Bilingual lexical access: what's the (hard) problem? Biling. Lang. Cogn. 9, 153-166.

Gollan, T. H., Montoya, R. I., Cera, C. M., and Sandoval, T. C. (2008). More use almost always means a smaller frequency effect: aging, bilingualism, and the weaker links hypothesis. J. Mem. Lang. 58, 787-814.

Green, D. W. (1986). Control, activation and resource: a framework and a model for the control of speech in bilinguals. Brain Lang. 27, 210-223.

Green, D. W. (1998). Mental control of the bilingual lexico-semantic system. Biling. Lang. Cogn. 1, 67-81. the other then speakers from code-switching communities may not show such an advantage (see Green, 2011). However, skills in code-switching may elicit advantages of another type. Skilled code-switchers shape verbal resources from one language to the current context. They may be adept more generally at seeing how one verbal form can be transformed into another to yield a novel meaning (e.g., turning a noun such as "piano" into a verb as in "she pianoed him"). Alternatively, and perhaps more plausibly, cerebellar circuits may be specialized and so skills in adapting words will dissociate from the ability to adapt non-verbal objects (e.g., seeing how a pen might be used as a clothes peg) Such specialization indicates a difference in the correlates of frontal versus cerebellar control processes.

We suggest, in conclusion, that differences in the control demands on bilinguals from different behavioral ecologies are a further source of individual variance in executive control. The contexts of language use may then temper the cognitive advantages of bilingualism and be relevant to understanding the effects of stroke on speech recovery in bilinguals.

\section{ACKNOWLEDGMENT}

This work was supported by the Wellcome Trust.

Green, D. W. (2011). “Bilingual worlds," in Language and Bilingual Cognition, eds V. Cook and B. Bassetti (New York: Psychology Press), 229-240.

Green, D. W., Parker-Jones, O., and Price, C. J. (2011). Bilingual processing: increased demands on the speech pipeline? in International Symposium on Bilingualism. Colloquium 224, Oslo.

Grosjean, F. (1998). Studying bilinguals: methodological and conceptual issues. Biling. Lang. Cogn. 1, 131-140.

Hernandez, A. E., Martinez, A., and Kohnert, K. (2000). In search of the language switch: an fMRI study of picture naming in Spanish-English bilinguals. Brain Lang. 73, 421-431.

Hoshino, N., and Thierry, G. (2011) Language selection in bilingual word production: electrophysiological evidence for cross-language competition. Brain Res. 1371, 100-109.

Kerns, J. G., Cohen, J. D., MacDonald, A. W. III, Cho, R. Y., Stenger, V. A., Aizenstein, H., and Carter, C.S. (2004). Anterior cingulate conflict monitoring and adjustments in control. Science 303, 1023-1026.

Kotz, S. A., and Schwartze, M. (2010). Cortical speech processing unplugged: a timely subcortico-cortical framework. Trends Cogn. Sci. 14, 392-399.

Kovelman, I., Baker, S. A., and Petitto, L. A. (2008). Bilingual and monolingual brains compared: a functional magnetic resonance imaging investigation of syntactic processing and a possible "neural signature" of bilingualism. J. Cogn. Neurosci. 20, 153-169.
Kroll, J. F., Bobb, S. C., and Wodniecka, Z. (2006). Language selectivity is the exception, not the rule: arguments against a fixed locus of language selection in bilingual speech. Biling. Lang. Cogn. 9, 119-135.

Linck, J. A., Kroll, J. F., and Sunderman, G. (2009). Losing access to the native language while immersed in a second language. Psychol. Sci. 20, 1507-1515.

Macizo, P., Bajo, T., and Martin, M. C. (2010). Inhibitory processes in bilingual language comprehension: evidence from Spanish-English interlexical homographs. J. Mem. Lang. 63, 232-244.

Marien, P., Engelborghs, S., Fabbro, F., and De Deyn, P. P. (2001). The lateralized linguistic cerebellum: a review and a new hypothesis. Brain Lang. 79, 580-600.

Nakamura, K., Kouider, S., Makuuchi, M., Kuroki, C., Hanajima, R., Ugawa, Y., and Ogawa, S. (2010). Neural control of cross-language asymmetry in the bilingual brain. Cereb. Cortex 20, 2244-2251.

Philipp, A. M., and Koch, I. (2009). Inhibition in language switching: what is inhibited when switching between languages in naming tasks? J. Exp. Psychol. Learn. 35, 1187-1195.

Rodriguez-Fornells, A., Rotte, M., Heinze, H. J., Nösselt, T., and Münte, T. F. (2002). Brain potential and functional MRI evidence for how to handle two languages with one brain. Nature 415, 1026-1029.

Silveri, M.C., Leggio, M. G., and Molinari, M. (1994). The cerebellum contributes 
to linguistic production: a case of agrammatism of speech following right hemicerebellar lesion. Neurology 44, 2047-2050.

Snyder, H. R., Hutchison, N., Nyhus, E., Curran, T., Banich, M. T., O’Reilly, R. C., and Munakata, Y. (2010). Neural inhibition enables selection during language processing. Proc. Natl. Acad. Sci. U.S.A. 107, 16483-16488.

Van Hell, J. G., and Dijkstra, A. (2002). Foreign language knowledge can influence native language performance in exclusively native contexts. Psychon B Rev, 9, 780-789. van Heuven, W. J., and Dijkstra, T. (2010). Language comprehension in the bilingual brain: fMRI and ERP support psycholinguistic models. Brain Res. Rev. 64, 104-122.

Von Studnitz, R. E., and Green, D. W. (2002). Interlingual homograph interference in German-English bilinguals: Its modulation and locus of control. Biling: Lang. Cogn. 5, 1-23.

Wu, Y. J., and Thierry, G. (2010a). Investigating bilingual processing: the neglected role of language processing contexts. Front. Psychol. 1:178. doi: 10.3389/fpsyg.2010.00178
Wu, Y. J., and Thierry, G. (2010b). Chinese-English bilinguals reading English hear Chinese. J. Neurosci. 30, 7646-7651.

Conflict of Interest Statement: The author declares that the research was conducted in the absence of any commercial or financial relationships that could be construed as a potential conflict of interest.

Received: 18 February 2011; paper pending published: 30 March 2011; accepted: 09 May 2011; published online: 19 May 2011.
Citation: Green DW (2011) Language control in different contexts: the behavioral ecology of bilingual speakers. Front. Psychology 2:103. doi: 10.3389/fpsyg.2011.00103

This article was submitted to Frontiers in Language Sciences, a specialty of Frontiers in Psychology.

Copyright (c) 2011 Green. This is an openaccess article subject to a non-exclusive license between the authors and Frontiers Media SA, which permits use, distribution and reproduction in other forums, provided the original authors and source are credited and other Frontiers conditions are complied with. 